\title{
The seismological correspondence at the Observatory of the Alberoni College in Piacenza
}

\author{
Matteo Cerini $\left({ }^{1}\right)$ and Graziano Ferrari $\left(^{2}\right)$ \\ (') Osservatorio Geofisico Alberoni, Piacenza, Italy \\ (') Istituto Nazionale di Geofisica e Vulcanologia, Bologna, Italy
}

\begin{abstract}
The Observatory of Collegio Alberoni in Piacenza boasts a long tradition of observations in the field of the Earth Sciences. Founded first of all as an astronomical observatory in 1751 it gradually specialized also in meteorological observation starting in 1802 and that of instrumental seismology starting in 1861. The instrumental observation of earthquakes in the modern sense started in the 1920s and is documented by an epistolary archive of some 200 letters (1913-1972) described here in brief. The Observatory has a broad-ranging initiative ongoing for the recovery of the historical scientific wealth of its long tradition in which the letters themselves play a very important role.
\end{abstract}

Key words history of seismology - Alberoni Observatory - seismic instruments

\section{Introduction}

The Alberoni College in Piacenza have a long and important tradition of research in the field of Earth Sciences. An astronomical Observatory was founded at the College in 1751 following the initiative of Cardinal Giulio Alberoni (1664-1752). In 1802, regular meteorological observations started at the Observatory. At the moment the first measures have not been found, we have only the register from 1805 to 1809 preserved at the Palatina Library of Parma and from 1833 to 1868 at the Alberoni College.

Seismological observations started in 1861 but in the historical registers of the Meteorolo-

Mailing address: Dr. Matteo Cerini, Osservatorio Geofisico Alberoni, Via Emilia Parmense, 29100 Piacenza, Italy: e-mail: ossgeoalberoni @ virgilio.it gical Observatory, working since 1802, inherent traces of the first seismic data were found. The promoter was Father G.B. Manzi, science teacher and Director of the Meteorological Observatory (fig. 1). In 1870 G.B. Manzi revived meteorological observation on new bases and had a meteorological tower built with adjacent dome for the astronomical observations. Besides making stable and continuous the meteorological reliefs, Manzi contributed, experimentally, to carry out observations with a Cavalleri pendulum seismograph. The parametric figures related to the rudimentary seismic instrument were never included in the registers and the spaces reserved to it were eliminated after a few months. Activity was developed, like the meteorological one, in the rooms at the second floor, where there is still the classroom of physics.

In 1874 Manzi bought a Bertelli one common prism tromometer, and then one Galli type seismoscope, one Galli Brassart seismic warning device (fig. 2) and one Agamennone seismoscope. Regular tromometric and geomagnetic observations were carried out from 1883 to 1915 (fig. 3). 


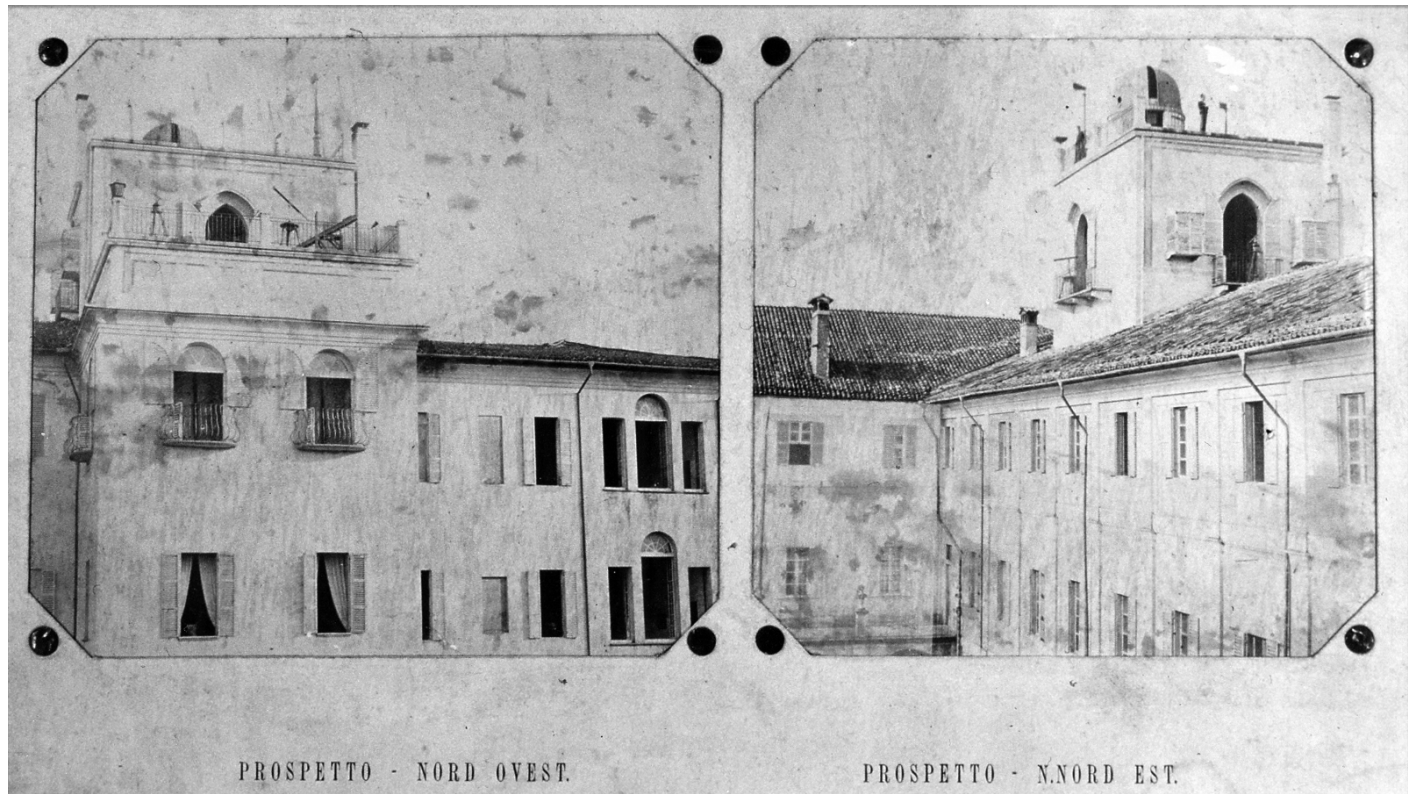

Fig. 1. The Alberoni Observatory in a photograph of the end of 19th century (Archive of the Ufficio Centrale di Ecologia Agraria, Rome).

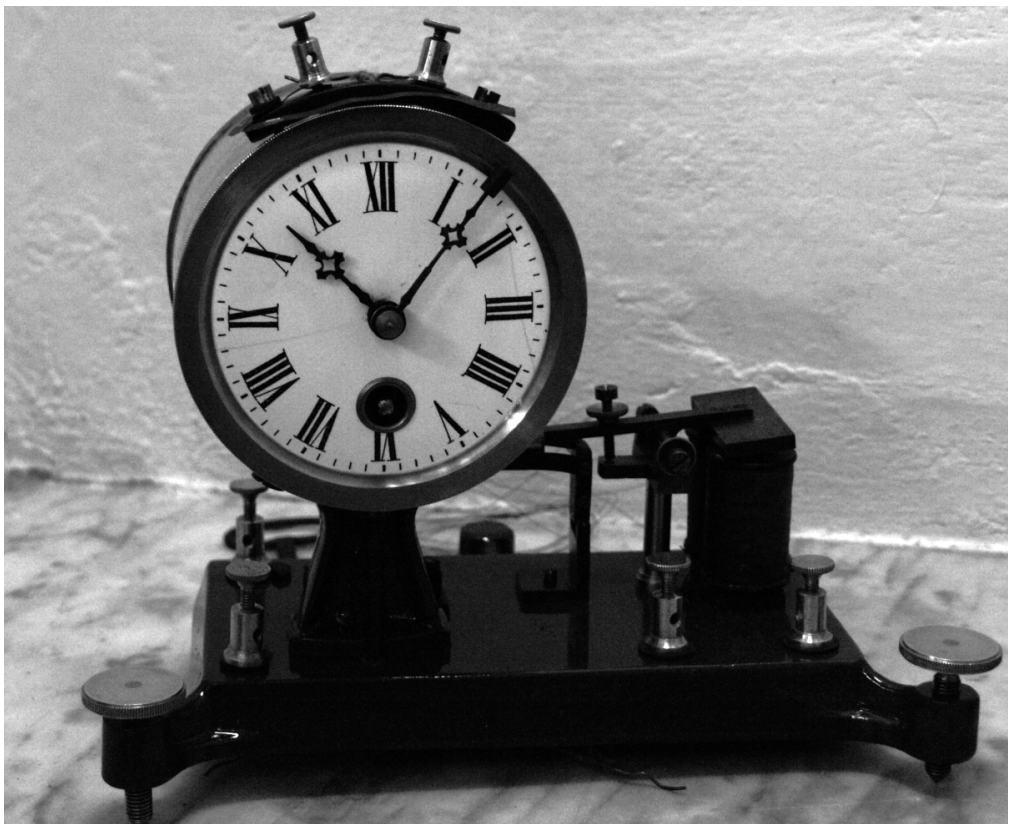

Fig. 2. Galli-Brassart seismic worning device. 
OSSERVAZIONI MAGNETICHE E MICROSISMICHE
Mese
d) Agoste 1883

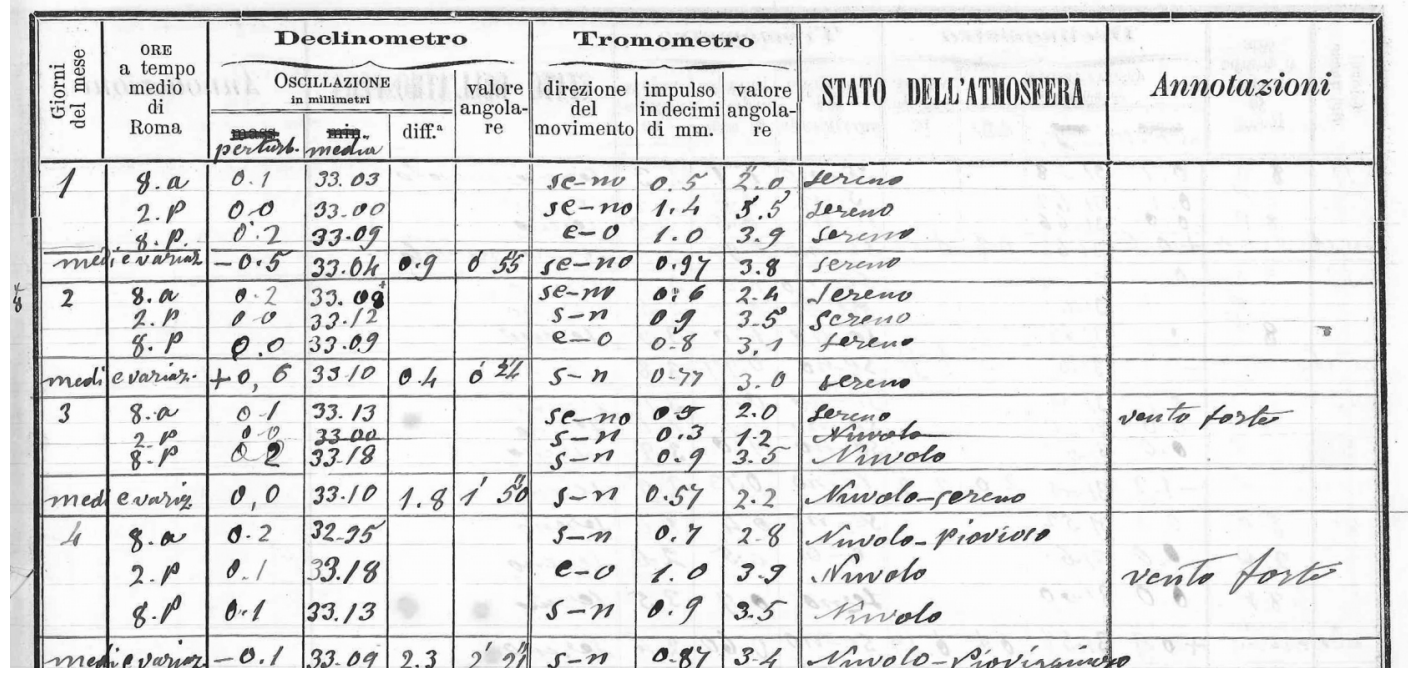

Fig. 3. Tromometric and geomagnetic observations from the register preserved at the Alberoni Observatory.

The first and significant collaborations were made with the Moncalieri Observatory (close to Turin) and the seismic observations were regularly sent to the Ufficio Centrale di Meteorologia e Geodinamica (UCMG - Central Office of Meteorology and Geodynamics) of Rome.

We have meager pieces of information on the relationship between Manzi and the exponents of the Italian scientific community. We also have not much news on the management of the scientific section of the Alberoni College. In the archives of the Institute, there is only one invoice related to the purchasing of meteorological instrumentation.

Up to here the story has been told by various published, or unpublished and fragmentary testimonies. In the 1920s the history of the modern seismological Observatory started, largely documented by the correspondence archive of the Observatory itself. From letters dated 1919-1920, we have the first indication about the interest of Pietro Andreoli, who succeeded Manzi in 1914, to buy more suitable and modern instrumentation for the seismic section of the observatory, which still did not have seismographs for continuous recording.

\section{The archive of scientific correspondence in the recent history of the Alberoni Observatory}

The archive is made up just over 200 letters received between 1913 and 1972, above all of a seismological nature. More correspondence makes up the contemporary collection. The most assiduous correspondent was Giovanni Agamennone with 48 letters between 1913 and 1939 , many of which dedicated to the horizontal seismograph designed by the scholar and also installed at the Observatory. Another assiduous letter-writer was Pietro Caloi with 20 letters between 1932 and 1948. The graph of fig. 4 shows the number of letters for the five-year period contained in the Observatory's epistolary collection. The letters were catalogued and scanned in the early 1990s within the scope of the Tromos Project (INGV-SGA, 1990-2007). 


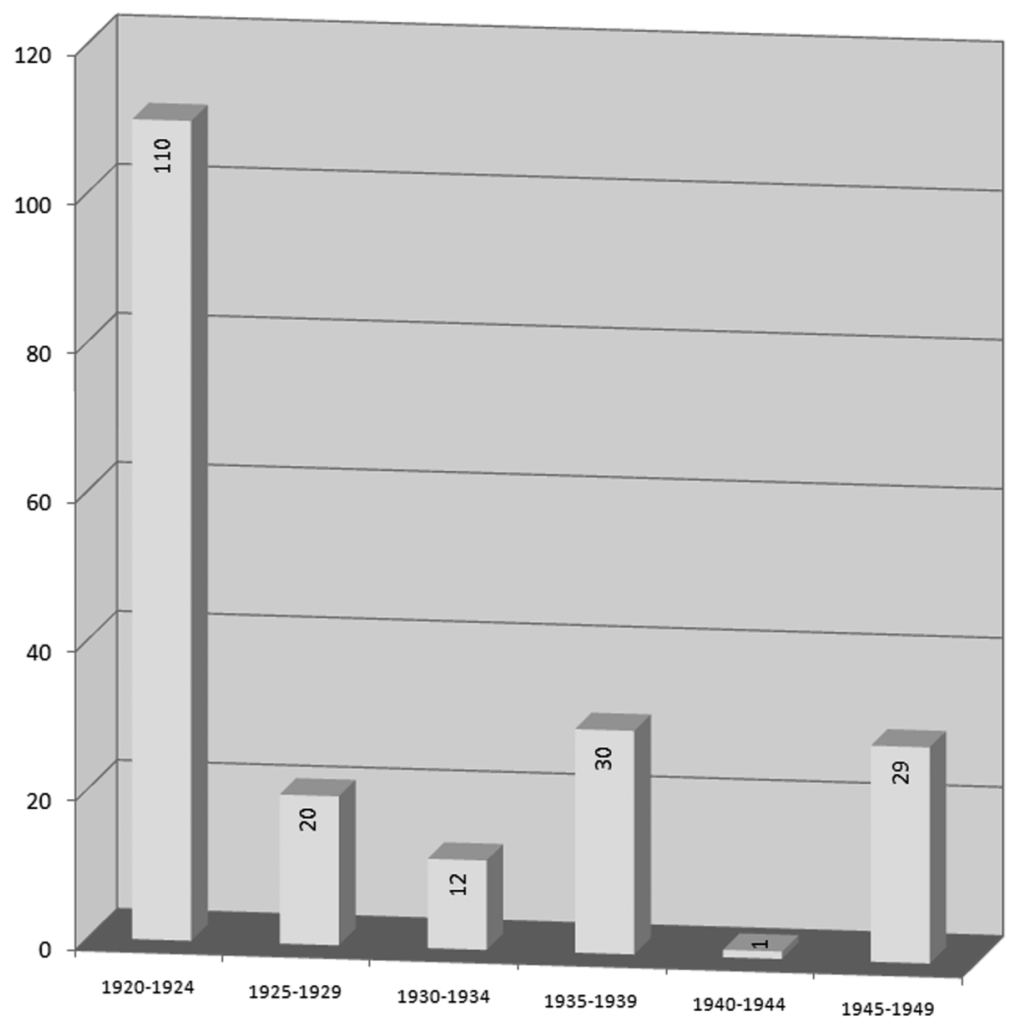

Fig. 4. Number of letters for five-years period of the Alberoni Observatory epistolary from 1920 to 1950 . After this period few letters survived.

Relations with the main designers of Italian and foreign seismic instruments are documented by numerous letters: 6 letters of the instruments factory Wiechert Bertels in 1923, 6 letters of Vicentini from 1924 to 1927, 1 of Conrad in 1924 and 7 letters between 1922 and 1923 of Giulio Grablovitz, director of the Geodynamic Observatory of Casamicciola (Isola d'Ischia Southern Italy). The letters tell the story of how one of the best equipped observatories of its day was born.

On 7th July 1921 one Agamennone horizontal pendula microseismograph built at the UCMG, was sent to Piacenza; it was placed in a room at the ground floor of the building where Manzi performed the geomagnetic and microseismic observations (fig. 5). Andreoli pressed to the director of UCMG Luigi Palazzo to have a three component version of the Agamennone seismograph in order to complete the equipment, but the answer was negative, because they could not make structural changes to the instrument under construction.

In May 1922 a system for the reception of the chronometric signals, used for correcting the system joined to the instrument, was lent from the maritime military arsenal of Spezia.

In the summer of 1922 Giovanni Agamennone personally tested his microseismograph. However the first seismograms date back to 1921, even though part of them were not signed. The instrumental replacement allowed the Observatory to be included in the national seismic bulletins. 


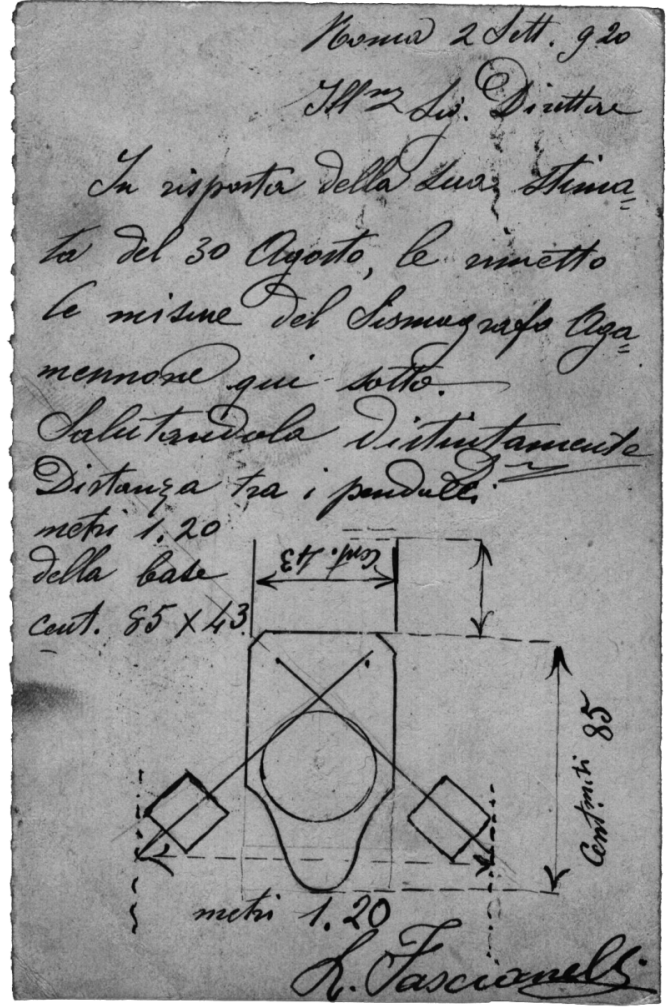

Fig. 5. Card from Luigi Fascianelli, the official instrument maker of the Central Office of Meteorology and Geodynamics, to Andreoli, the director of the Observatory (September 2nd, 1920) in which a sketch of the Agamennone seismograph with two horizontal components is reported with the related measurements.

In March 1923 the seismic Observatory was equipped with one Wiechert astatic horizontal seismograph with a mass of $1000 \mathrm{Kg}$. The instrument coming from the Hydrographic $\mathrm{Ob}$ servatory of the Royal Navy of Pola, was assigned (under agreement) to internal use in the Institute, but even for providing data to external researchers. During the first phase of the complex negotiation, it seemed that the instrument would remain with a government and not a private facility. Andreoli took the transport upon himself. The seismograph was in fairly good repair. The assembly and the testing of the deli- cate and sophisticated seismograph were performed by the firm Bartels of Gottingen (fig. 6). There are few pieces of information related to the Conrad horizontal pendulum seismograph, installed in 1924; it was rarely used.

One of the four rooms of the Observatory, was turned into an archive and to smoke paper for mechanical recording. Some accessories for the procedures of smoking were given up with the Wiechert seismograph.

In November 1924 Andreoli got in touch with Giuseppe Vicentini renowned seismologist and teacher of Physics at Padua University. The seismic center of the Alberoni College needed a vertical component instrument. The triaxial system (two horizontal seismographs and one vertical) would have been provided with magnetic damping in comparison with the previous not damped ones; so there would be increases in periods of masses oscillation cutting down the weight. The two horizontal components would have been separated from each other (fig. 7). The wait was rather long because of organizational problems inherent in the construction of the microseismograph. The instrument with vertical pendulum mass was fitted with a mercury thermal compensator that made up for the variations in temperature of the metallic arm. The job was commissioned from Ferro's scientific shops of Turin. The microseismograph was installed in 1927.

Obviously the scientific equipment was put on columns and concrete separated from the structure of the building, so that they could better transmit the seismic waves to the instruments. The planners of the construction of the building supports were very shrewd.

From 1925 the direction of the Observatory was managed by Mr. Zeppieri, the first author of the scientific publications of the Alberoni College. In the 30's, the instrumental collection put the seismic Observatory among the most equipped in Italy. From 1935 the empirical figures related to the macroseismic local fields and to parametric instrumental ones were telegraphically transmitted to the Central Office of Meteorology and Geophysics. The station books were drawn up with scientific rigor and included information on the damage caused by the earthquakes. There are several numerical and 


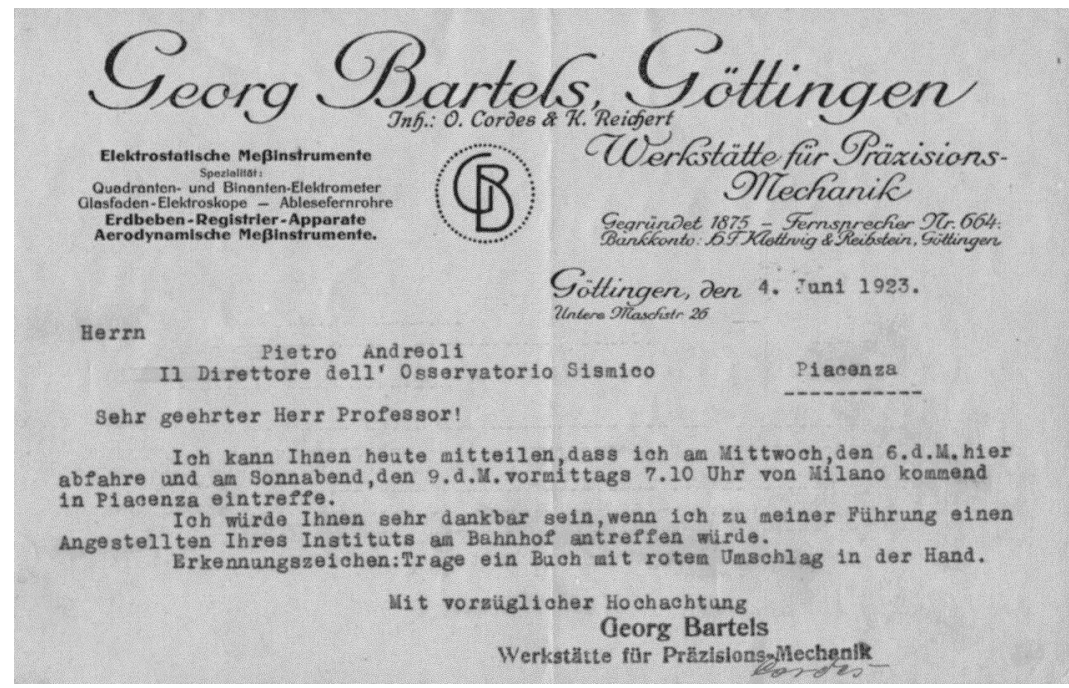

Fig. 6. Letter of the Bertels farm concerning the installation of the Wiechert seismograph at the Alberoni Observatory.

graphic figures inherent in the instrumental constants. The recordings were partially preserved up to 1927 . From 1928 to 1943 there was no discontinuity. From 1944 only the seismograms with seismic events were stored in the archives. Altogether there are 17,305 historical seismograms $(15,325$ from Wiechert astatic seismograph, 1,601 from Vicentini microseismograph, 375 from Agamennone seismograph and 4 from Conrad).

In the sixties the activity of the Agamennone seismograph was suspended, the Vicentini in 1970 and the Wiechert in 1996. Father Cesare Pizzi, who succeeded Emidio Prata (director in the 40's and 50's), wanted further instrumental updating. To better study the instrumental and local macroseismic activity and to provide more reliable data to the National Institute of Geophysics, a seismometric triad with analogical writing apparatus and electronic amplification was purchased. The data were no longer furnished regularly to the Institute after the sixties. An agreement was signed in March 1976. The earthquake locations were made by a rudimentary computerized system of calculation. In 1992 after the death of Cesare Pizzi, the
Observatory was inactive for about six months.

Currently the Observatory has digital instruments. The archive has been reorganized and it was made a computerized cataloguing of all seismograms. Data related to the events have been included in a database. The historical instrumentation was restored in 2008.

\section{Conclusions}

The long and important scientific tradition of the Observatory of the Collegio Alberoni is documented by manuscripts of meteorological recordings from the start of the 19th century and seismic ones from the 1880s and a reduced, but important historic epistolary collection from 1913 to 1972. The latter in particular documents the phase of updating the seismic instrumental equipment of the Observatory that made it one of the most modern of the day. The Observatory has a far-reaching initiative ongoing for the recovery of the historical scientific assets of its long tradition. A complete cataloguing has been undertaken of the over 17,305 seismograms recorded from 1921 to 1996 with 


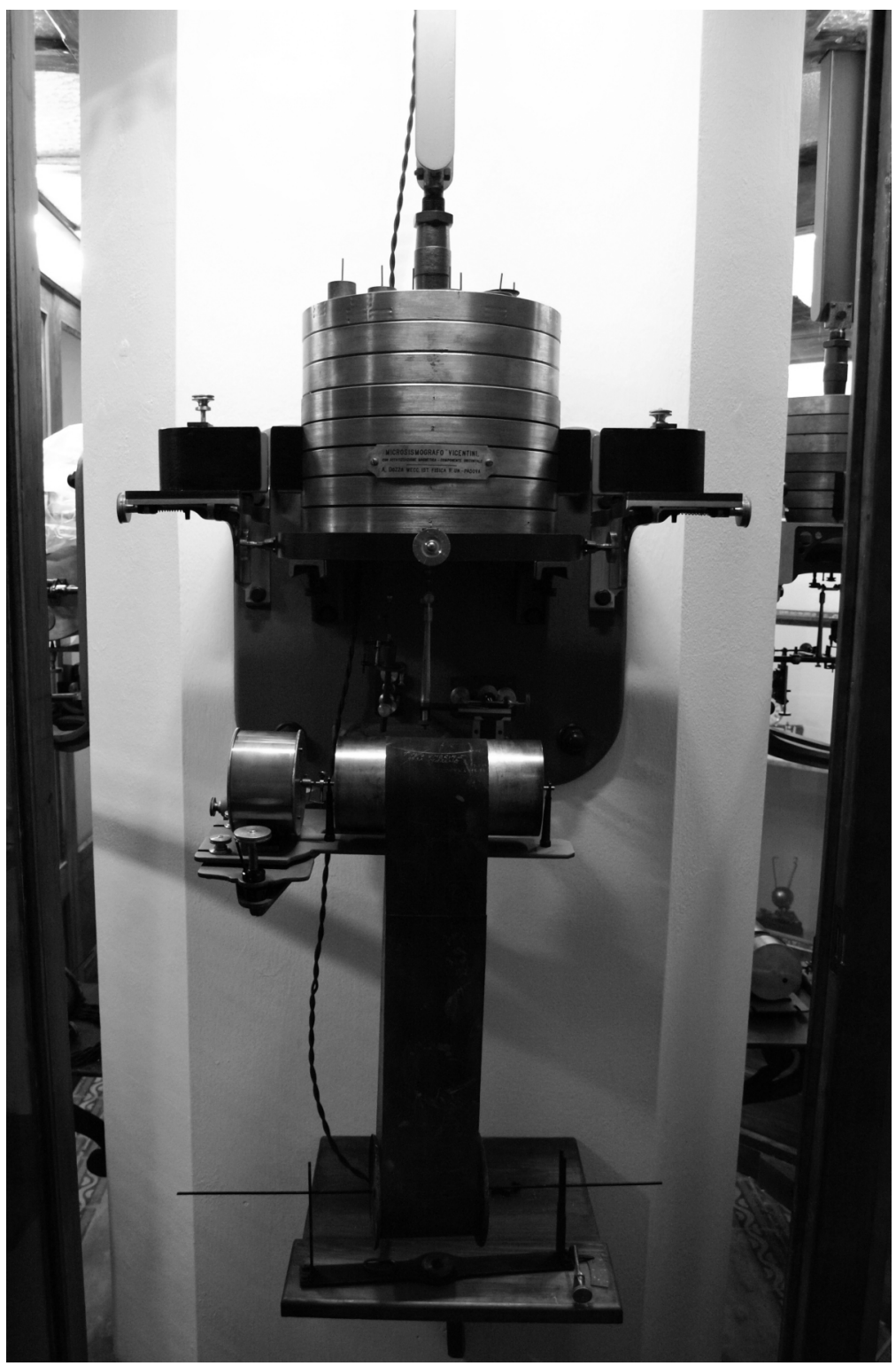

Fig. 7. Vicentini Horizontal seismograph preserved and recently restored at the Alberoni observatory.

the mechanical recording instruments and the cataloguing and the digital reproduction of the whole epistolary collection. Also being completed is the restoration of all of the historical instrumentation. The Observatory, which pre- serves its current activity of instrumental monitoring, takes part in the initiative of the SISMOS project of virtual recomposing of the historical network of the scientific observation of earthquakes in Italy. 